\title{
Special Section of Invited Papers from the 30th Australasian Conference on Information Systems
}

\section{Deborah Bunker}

The University of Sydney, Australia

d.bunker@sydney.edu.au

\section{Annette Mills}

University of Canterbury, New Zealand

annette.mills@canterbury.ac.nz

\section{Doug Vogel}

Harbin Institute of Technology, China

isdoug@hit.edu.cn

As Program Chairs of the 30th Australasian Conference on Information Systems (ACIS) we were privileged to work with a wonderful group of Best Paper authors as well as a select panel of reviewers for the Australasian Journal of Information Systems (AJIS 2019) Special Section.

ACIS2019 was the 30th anniversary of the Australasian Information Systems Conference and as such has symbolic significance for our community. These papers reflect the diversity of ideas and inclusiveness within our community and very high standards of academic contribution.

These papers cover a range of topics which focus on: tool development to eliminate filter bubbles in social networks; understanding how peer influence impacts teenager's adoption of IS security guidelines; applying a social constructivist perspective on digital transformation; using decision support systems in the context of cyber-physical systems; and using an intelligent agent-based IS framework for dynamic demand environments.

For this Special Section, ACIS 2019 Best Papers were initially improved and extended by their authors and then double blind reviewed by our review panel members. Authors were then allowed the necessary time to respond and further improve their papers.

We sincerely thank our reviewer panel for their time and expertise to assist authors during what was a particularly difficult and uncertain period at the onset of the COVID-19 pandemic.

We are sure that you will agree that these papers represent some of the best of what the Australasian information systems community has to contribute to knowledge development in information systems.

Deborah Bunker, Annette Mills and Doug Vogel

\section{AJIS Special Section Co-Editors}

Copyright: (c) 2021 authors. This is an open-access article distributed under the terms of the Creative Commons Attribution-NonCommercial 3.0 Australia License, which permits noncommercial use, distribution, and reproduction in any medium, provided the original author and AJIS are credited. 
doi: https://doi.org/10.3127/ajis.v25i0.3449

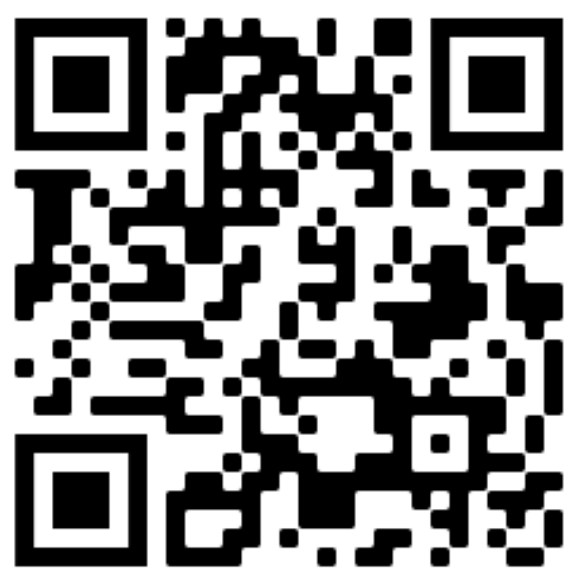

